\title{
La pandemia Covid-19 y la continuidad de los procesos de formación de los profesionales de la salud: virtualización de las experiencias de aprendizaje en la Sociedad Argentina de Diabetes
}

\author{
The Covid-19 pandemic and the continuity of the training processes \\ of health professionals: virtualization of learning experiences \\ in the Argentine Society of Diabetes
}

El año 2020 se nos presentó a todos como un año diferente en el que nos vimos obligados, individualmente y como comunidad, a generar formas distintas de comunicación e intercambio. Transcurría febrero y los docentes de la Sociedad Argentina de Diabetes (SAD) generábamos propuestas para desarrollar durante el año, compartiendo reuniones y tratando de responder inquietudes surgidas de los debates, planificando los temas, a quiénes dirigirnos o qué competencias queríamos desarrollar. Pero marzo nos sorprendió con el contexto de aislamiento sanitario producto de la pandemia y esto generó un desafío en materia educativa con más incertidumbres que certezas, dentro de un marco de mucha angustia en lo personal y laboral.

En los primeros meses del año, cuando nos vimos compulsivamente llevados a la modalidad virtual como la única que nos permitiría sostener la formación de nuestros colegas en la especialidad, debimos tomar la decisión de adecuar nuestras propuestas de formación presenciales o suspenderlas hasta que todo volviera a la normalidad, sin fecha probable, con la incertidumbre que aún hoy atravesamos. Decidimos adecuarnos y trabajar desde los aprendizajes sobre la modalidad virtual que, como educadores de la $S A D$, ya veníamos construyendo hacía un par de años. La SAD decidió salir a la comunidad con propuestas renovadas bajo esta modalidad; se generó así una verdadera explosión y revitalización de los cursos y diplomaturas, que llegaron a tener su número record de 2.400 cursantes en 18 cursos brindados durante todo 2020 .

\section{Un poco de historia}

La SAD comenzó a transitar este camino en 2016, con el primer curso virtual, y lo continuó en 2017 con nuevos cursos en línea, y con el desarrollo de un entorno virtual propio que requirió capacitación especializada en el personal de la SAD. Además, también se inició el camino de las diplomaturas a través de la asociación con instituciones educativas universitarias.

En 2018 apostamos fuertemente a capacitar a los directores de cursos y comités de trabajo a través del curso de posgrado "Diseño y gestión de aulas virtuales de aprendizaje" (Res. No 1458/ 18-C.D.), de la Facultad de Medicina de la Universidad Nacional del Nordeste, en el cual participaron directores de cursos, coordinadores de comités y diplomaturas. Esto significó un interesante background de experiencias previas que permitieron avanzar desde una necesaria "enseñanza remota de emergencia" hacia el verdadero online learning que todo cuerpo académico virtual de excelencia pretende para sus propuestas'.

A partir de aquí, se readecuaron las propuestas formativas presenciales como la Escuela de Graduados, que se convirtió en dos Diplomaturas Superiores, nivel inicial y avanzado, de la que egresaron más de 100 cursantes y que en 2021 abrirá su tercera cohorte. Se llevaron adelante diplomaturas universitarias, además de 16 cursos dictados por la SAD.

Las experiencias vivenciadas en las distintas actividades docentes nos movilizaron y generaron cuestionamiento sobre nuestra propia práctica y en las de todo el equipo docente al interrogar- 
nos: ¿qué hacemos en nuestras clases?, ¿cómo las planificamos?, si hacemos una autoevaluación de lo que dimos, ¿eso nos permite reelaborarla? Y, como dice Mariana Maggio (2018): "Para que las clases sean experiencias que docentes y estudiantes queramos vivir, hay que reinventarlas. Queremos estar en clase porque lo que sucede es único y no está en YouTube. Porque lo que sucede en clase es algo que sabemos que nos va a inspirar, que nos va a emocionar, que nos va a transformar. Queremos estar en clase porque lo que allí se crea es original y yo quiero ser parte de esa creación"4. Y para ello, nos propone recorrer escenarios, experiencias y producciones que nos interpelan como docentes universitarios. Invita a entender la clase como un diseño de autor y a la invención constante en todos los ámbitos, enriquecida por los nuevos consumos culturales, y podemos decir que hemos descubierto y vivenciado muchos momentos como estos donde nuestros docentes nos movilizaron y emocionaron, y aquello que nos parecía imposible empezó a transformar nuestra mirada.

Ante esta importante propuesta respondimos algunos interrogantes para consolidar un modelo pedagógico distintivo de la $S A D$, para la modalidad virtual y para toda formación profesional en la especialidad. En este editorial, rescatamos aquellos que nos permiten reflexionar sobre este proceso de virtualización implementado: ¿qué roles docentes nos demandó modificar la virtualidad?, ¿en qué rol habilitamos a los cursantes de nuestras propuestas, colegas del campo de la salud interesados en la diabetes?, ¿qué implicancias futuras tiene toda esta experiencia lograda para una Sociedad científica como la nuestra? Vamos a recorrerlas.

Podemos afirmar que hemos asumido nuevos roles docentes vinculados a las demandas de esta modalidad y completamente diferentes a los del docente tradicional presencial. En este sentido, el profesor virtual cumple con diferentes roles, a los que no estaba exigido, si se quiere, en la presencialidad²:

- Rol social: porque un punto clave en la virtualidad es el distanciamiento, justamente, que ahora lo experimentamos, y esa distancia física genera innumerables repercusiones en torno al desgranamiento o la deserción, inclusive, en los cursos virtuales, entonces, no puede desconocerse lo social.

- Rol pedagógico: propios de la enseñanza y el aprendizaje de los contenidos disciplinares y las prácticas profesionales que se pretenden.
- Rol de dirección: generar sistemas de gestión y de dirección, que son fundamentales, para que funcione el equipo docente.

- Rol técnico: al integrarse las nuevas tecnologías (así como hemos aprendido a utilizar el pizarrón, la pizarra eléctrica, el power point, el retroproyector $y$, en su momento, el proyector de filminas), se necesita una capacidad técnica específica. Es así que nos corremos del docente o formador como "proveedor" o "repetidor" de contenidos o prácticas determinadas, para convertirnos en gestores del contenido o de los conocimientos que ponemos en juego en los cursados. Es por ello que varios de nuestros docentes participaron durante 2020 en los tres niveles de formación de gestión de Aulas Virtuales SAD-Universidad Nacional del Nordeste (UNNE) para incorporar técnicas específicas de enseñanza y aprendizaje.

Por otro lado, se menciona que existen aspectos organizativos previos que deben tenerse en cuenta de manera insoslayable3. Si bien es cierto que ya en la presencialidad la improvisación tiene malas consecuencias porque no nos permite potenciar el aprendizaje, en la virtualidad es todavía más nefasta la no planificación y estudio previo cuidadoso de la propuesta virtual que debe presentarse como un recorrido coherente e integrado, que genere una experiencia de aprendizaje profundo en los cursantes.

Tanto la diversificación de roles, como el hincapié en la planificación y permanente reajuste fueron notas distintivas de nuestras prácticas durante 2020.

Un pilar central a destacar en este perfilado de prácticas sobre las que reflexionamos son las tutorías virtuales desarrolladas por los equipos de los cursos, que se centraron en el rol de "facilitador" de los aprendizajes, verdaderos nexos pedagógicos, disciplinares y de apoyo social de los cursantes con las propuestas de cursado. Entendimos que el tutor virtual tiene fundamentalmente que realizar acciones de orientación, ayuda o consejo para alcanzar diferentes objetivos. Fuimos "descubriendo" en los equipos docentes quiénes tenían este perfil, ya que la complejidad del rol no se desarrolla o presenta de manera espontánea, sino que requiere de determinadas condiciones personales y profesionales para implementarlo. Hemos observado cómo los tutores se preocuparon por integrar a los cursantes al entorno virtual al desarrollar vínculos humano-formativos5, resolver dudas de comprensión de los contenidos que se 
presenten, pero desde la guía, los interrogantes para reflexionar, las orientaciones. En síntesis, como tutores, intentaron facilitar la integración del cursante a la acción formativa, a su propio proceso de formación. Éste es el rol que pretendimos habilitar con las propuestas de aprendizaje: la de un cursante activo, revisor de sus propias prácticas y conocimientos, capaz de ejercer competencias de resolución de problemas clínicos, centrados en contextos reales, prevalentes y actuales.

Para cerrar, consideramos que lo experimentado en 2020 marca un antes y un después. Podríamos denominarlo año bisagra en muchos as-

\section{BIBLIOGRAFÍA}

1. Hodges C, Moore S, Lockee B, Trust T, Bond A. The difference between emergency remote teaching and online learning. EDUCAUSE Review, 2020. Disponible en: https://er.educause.edu/articles/2020/3/the-differencebetween-emergency-remote-teaching-and-online-learning. 2020.

2. Ryan $S$, et al. The virtual university. The Internet and resource-based learning. Routledge, Londres 2000. pectos, y lo educativo no quedó afuera. La SAD ha comenzado un camino de virtualización de sus propuestas al fortalecer y expandir fronteras y alcances territoriales que redundarán en beneficio tanto para el personal de salud involucrado en SAD como en los pacientes, que sin duda, son nuestro objetivo final.

\section{Silvia Gorbán de Lapertosa, Patrica Demuth, Camila Matus, Carla Musso, Mabel Ferraro Comisión de Educación (CEDEI) de la Sociedad Argentina de Diabetes}

3. Cabero-Almenara J. Formación del profesorado enTIC: el gran caballo de batalla. Comunicación y Pedagogía: Nuevas tecnologías y recursos didácticos 22004; 195:27-31.

4. Maggio M. Reinventar la clase en la Universidad. Paidós, Buenos Aires 2018.

5. Llorente Cejudo $\mathrm{M}$ del C. La tutoría virtual: técnicas, herramientas y estrategias. EDUWEB. Revista de Tecnología de Información y Comunicación en Educación EDUWEB 2007; 1. 